\title{
A efetividade de programas sociais de acesso à educação superior: o caso do ProUni*
}

\author{
Luiz Alex Silva Saraiva** \\ Adriana de Souza Nunes***
}

SumÁrio: 1. Introdução; 2 . A educação superior e os setores público e privado; 3. Programas sociais e ampliação de acesso à educação superior; 4. Desempenho de programas sociais; 5 . Método; 6 . Análise dos dados; 7. Considerações finais.

Summary: 1. Introduction; 2. Higher education and public and private sectors; 3. Social programs and expansion of accessing to higher education; 4. Performance of social programs; 5. Method; 6. Data analysis; 7. Final considerations.

Palavras-chave: educação superior; desempenho; programas sociais; ProUni.

Key words: higher education; performance; social programs; ProUni.

Um dos efeitos do acirramento generalizado da competição verificado atualmente é o aumento da demanda social por educação, o que pressiona o sistema educacional a equilibrar a relação entre oferta e demanda, o que em parte pode ser feito via a criação de programas sociais na área. Criado pelo governo federal para buscar este ajuste, o Programa Universidade para Todos (ProUni) objetiva ampliar o acesso de brasileiros de afrodescendentes, indígenas e de baixa renda à educação superior, uma iniciativa ainda pouco discutida no âmbito da administração, programa que, neste estudo, tem sua efetividade avaliada a partir da ótica de seus beneficiários.

\footnotetext{
* Artigo recebido em jan. 2009 e aceito em out. 2010.

** Professor adjunto do Departamento de Ciências Administrativas e do Centro de Pós-Graduação e Pesquisas em Administração da Faculdade de Ciências Econômicas da Universidade Federal de Minas Gerais (UFMG). Doutor e mestre em administração pela UFMG. Bacharel em administração pela Universidade Federal de Sergipe (UFS). Endereço: Universidade Federal de Minas Gerais, Faculdade de Ciências Econômicas, av. Antonio Carlos, 6627 - Pampulha - CEP 31270-901, Belo Horizonte, MG, Brasil. E-mail: saraiva@face.ufmg.br.

*** Bacharel em administração pela Faculdade de Ciências Administrativas e Contábeis da Fundação Comunitária de Ensino Superior de Itabira (Funcesi). Endereço: rua Sebastião Damásio Alvarenga, 322 - Santa Tereza - CEP 35900-435, Itabira, MG, Brasil. E-mail: a.souzanunes@ gmail.com.
} 


\begin{abstract}
A pesquisa adotou uma perspectiva qualitativa, tendo sido abordados bolsistas do ProUni por meio de entrevistas semiestruturadas em profundidade. Os resultados revelam que embora este programa atenda às expectativas de inclusão no ensino superior, sendo-lhe atribuídas diversas expectativas e evidências de ascensão profissional e social, há críticas consideráveis, o que indica a necessidade de ajustes por parte dos formuladores de políticas públicas educacionais. Em que pese o escopo do ProUni, as conclusões indicam que, mesmo atingindo grande número de brasileiros, esta iniciativa mascara a necessidade de investimentos maciços em educação pública e de qualidade.
\end{abstract}

The effectiveness of social programs for accessing higher education: the case of ProUni

Growing competition nowadays observed brings as an effect a higher demand for education. This presses educational system to equilibrate the relation between supply and demand, what partially can be made through social programs creation. University for all program (ProUni) was created by Brazilian federal government to include afro-descendents, indigenous and low income Brazilians into higher education, a still little discussed initiative. In this paper we deal with its effectiveness evaluation from its beneficiary's optics. Our research adopted a qualitative perspective, approaching ProUni grant holders through interviews semi-structured in depth. Main results suggest that, although this program assists to the inclusion expectations in the higher education, being associated to it several expectations and evidences of professional and social ascension, there are critics, what indicates the need of adjustments on education public politics formulation. Besides scope of ProUni, conclusions show that even with reaching a lot of Brazilians, this program hires need of high investments in public and high quality education.

\title{
1. Introdução
}

Neste estudo se analisa a efetividade de programas sociais de acesso à educação superior a partir da ótica de seus beneficiários. Compondo um movimento mais amplo de alinhamento de paradigmas no campo da globalização como condição de inserção das sociedades na modernidade, a educação superior é pressionada a atender demandas crescentes e variadas (Barreiro e Terribili Filho, 2007). Visto que é cada vez mais difícil separar a educação de desenvolvimento, os governos se veem diante da necessidade de apresentar propostas que, mediante o uso racional de recursos financeiros, beneficiem o maior número de cidadãos. Para Barreiro e Terribili Filho (2007), um dos fundamentos da inserção no mundo competitivo atual é o domínio e a produção do conhecimento, que passam a ser um bem - identificando-se aí um dos papéis a que se destinam as universidades. Nessa perspectiva, as uni- 
versidades têm um importante papel na inclusão, promoção da participação e da independência das pessoas com necessidades educacionais especiais e dos demais grupos minoritários, possibilitando uma distribuição igualitária desse direito (Barbosa, 2002).

No Brasil, para fazer frente a esse contexto global, na década de 1990 já se travavam discussões entre a sociedade e o governo federal sobre melhorias na educação em todos os níveis, principalmente no nível superior, em que se destacavam os debates sobre a política de cotas nas universidades públicas. Mediante a necessidade de investimento, o governo federal em 2004 lançou o Programa Universidade para Todos (ProUni), com intuito de possibilitar e incentivar o estudo e o acesso a esse ensino a brasileiros de baixa renda, exalunos da rede pública do ensino médio ou de bolsistas integrais das escolas particulares. O programa oferta, por intermédio de parcerias com instituições de ensino superiores particulares, bolsas que cobrem integral ou parcialmente os custos das mensalidades. Em contrapartida, oferece às instituições abatimentos tributários no imposto de renda das pessoas jurídicas, na contribuição social sobre o lucro líquido, na contribuição social para financiamento da seguridade social e na contribuição para o programa de integração. Possui também uma política de quotas destinada aos alunos portadores de necessidades especiais, afrodescendentes ou indígenas, cujas vagas são distribuídas conforme a proporção dessas populações nos estados.

Segundo o Ministério da Educação (2009), o ProUni é uma iniciativa do governo federal que visa à diminuição das desigualdades sociais com a inclusão de brasileiros no ensino superior, reduzindo a defasagem de oferta nas universidades públicas. O ProUni engloba diversas expectativas e interesses por parte dos governantes, das instituições e dos estudantes: o governo federal, com a possibilidade de desenvolvimento do país, por meio da divulgação dos programas sociais desenvolvidos, objetiva o aumento de brasileiros no ensino superior, o que traz benefícios às instituições de ensino superior particulares, por meio da redução da carga tributária com abatimentos de alguns impostos e, para os estudantes, a possibilidade de acesso à educação superior.

As vagas destinadas ao ProUni têm sido intensamente discutidas, visto que, para se inscreverem, os beneficiários necessitam somente realizar a prova do Exame Nacional do Ensino Médio (Enem) e obter a nota média nacional - que nos últimos anos tem permanecido em torno de $45 \%$ aptos a concorrer às vagas - , com efeitos sobre o padrão de qualidade acadêmica das instituições de ensino superior particulares. Outras questões se relacionam ao desempenho do programa, à política nacional de acesso ao ensino superior, 
aos instrumentos de inclusão social, às alternativas ampliadoras de oferta das vagas na educação superior por meio de parceria com IES privadas, à mensuração dos efeitos da inclusão educacional superior no desenvolvimento do país e aos impactos na diminuição das desigualdades econômicas e raciais. Estes aspectos conferem relevância a este estudo por ele lançar um olhar analítico sobre os beneficiários e suas representações sociais quanto ao programa social. Além disso, visto que há milhares de brasileiros usufruindo o ProUni, o estudo é oportuno por possibilitar a análise de variáveis significativas do programa social enquanto política de inclusão social sob múltiplas óticas.

Após esta introdução, será apresentado um referencial teórico em que se discorre sobre a educação superior e suas configurações nos setores público e privado, o papel dos programas sociais na ampliação de acesso à educação superior, o desempenho de programas sociais e as representações sociais. Em seguida, será discutido o método usado para a elaboração do estudo, o que precede a análise dos dados e as considerações finais.

\section{A educação superior e os setores público e privado}

A educação historicamente esteve atrelada à percepção de desenvolvimento de uma sociedade, pois nenhum país pode aspirar ao desenvolvimento e à independência sem um sistema de educação superior consistente, uma vez que a importância desse nível de educação é cada vez maior na medida em que o conhecimento é mais importante do que os recursos materiais como fator de desenvolvimento humano (Barbosa, 2002). Pestana (2001) complementa esta visão ao afirmar que a educação é, hoje, primordial tanto para o pleno exercício da cidadania quanto para o desempenho de atividades cotidianas, sendo também elemento essencial para tornar a sociedade mais justa, solidária e integrada. A sociedade também tem atentado ao fato de que considerável número de pessoas não consegue acesso a uma educação adequada, situação que precisa ser mudada para o exercício pleno da cidadania.

Porém, mais escolarização e qualificação são insuficientes para as exigências dos postos de trabalho. Para Catani e Hey (2007), a questão de acesso à educação superior se embasa nas necessidades de maior qualificação no momento de se obter um emprego, e de melhor remuneração no mercado de trabalho. A educação superior contribui para o desenvolvimento sustentável e a melhoria da sociedade como um todo, ao formar profissionais qualificados e capazes de satisfazer às necessidades de todos os setores de atividades humanas, e a disseminar o conhecimento por meio da sua difusão (Lucchesi, 2005). 
Se na década de 1960 as políticas públicas brasileiras de investimentos em educação superior eram inicialmente direcionadas para atender às necessidades decorrentes da expansão do desenvolvimento econômico e às exigências impostas pelo mercado de trabalho (Souza, 1981), a expansão maciça neste segmento ocorreu nos anos 1970, quando surgiu a necessidade de absorção do grande número de alunos excludentes, aprovados nos exames vestibulares de universidades públicas, que não podiam ser admitidos por falta de vagas. Nesse quadro, as universidades particulares ganharam força, já que o Estado não supria tal carência (Sampaio, 2000). A partir de então, devido à demanda crescente, a educação se tornou um segmento de alta atratividade para empresários, tendo sido deixadas em segundo plano questões relevantes, como a formação de professores, a qualidade do ensino e, sobretudo, a política de oferta de vagas pelo Estado (Barreiro e Terribili Filho, 2007).

A partir da década de 1990, o governo federal passa a desenvolver iniciativas no campo das políticas públicas de educação para melhorar o desempenho da educação nacional, tendo sido apresentadas propostas de mudança da educação fundamental à superior. Algumas medidas foram tomadas com a finalidade de reduzir os custos e aumentar a eficiência e a produtividade do setor público, importantes para que o governo tivesse condições de adentrar no terreno da gestão da educação (Sousa e Freitas, 2004). Entre elas, pode-se citar a redefinição do papel do Ministério da Educação e do Conselho Nacional de Educação, possibilitados pelas Leis no 9.131, de 1995; 9.394 (Lei de Diretrizes e Bases da educação nacional), de 1996; e 10.172 (Plano Nacional de Educação), de 2001.

No que diz respeito à educação superior, a necessidade de reformulação era explícita no Plano Nacional da Educação (Brasil, 2001:29): “a educação superior enfrenta, no Brasil, sérios problemas, que se agravarão, se o Plano Nacional de Educação não estabelecer uma política que promova sua renovação e desenvolvimento". Esta lei propõe a elevação da taxa de escolarização da população de 19-24 anos para 30\% num período de 10 anos, o que resultará em mais 3,2 milhões de estudantes matriculados, consequentemente gerando aumento de procura pelo ensino superior. Após quase 10 anos, já há sinais de crescimento e amadurecimento do ensino superior no Brasil, um processo que ainda necessita de investimentos e melhorias. O país ampliou o número de cursos e instituições, possibilitando mais acesso da sociedade à informação, o que influencia o perfil do educando e do educador.

Todavia, trata-se de um processo de que participa ainda um reduzido número de estudantes, o que emperra o desenvolvimento das mudanças. Segundo Barreto e Schwartzman (1999), o principal problema nessa questão é 
a baixa oferta proporcionalmente à população do país. Catani e Hey (2007) afirmam que o problema de acesso ao ensino superior tem sua raiz nos anos 1990, quando evoluiu o número de estudantes no ensino médio, bem como seus concluintes, gerando pressão da população por continuidade dos estudos. Segundo os autores, o PNE não previu uma efetiva incorporação sustentável, pelo Estado, dessa demanda no ensino superior, o que explica a grande oferta de vagas em IES particulares, cujos custos estão fora do alcance da maior parte das famílias.

Apesar de investimentos na rede federal, que por sofrer de falta de recursos é ampliada de modo precário e fragilizado, a expansão de matrículas no ensino superior é sustentada pelo ensino privado, indicando que esta hegemonia na oferta de vagas tende a se consolidar (Catani e Hey, 2007). Para Vaidergorn (2001), as políticas para o nível superior no Brasil vêm gerando resultados duvidosos quanto ao progresso técnico-científico e ao bemestar, pois as desigualdades nos extremos vêm se aprofundando. Para ele, algumas iniciativas facilitam a proliferação de cursos particulares, que vêm se tornando empresas poderosas e rentáveis, ficando o Estado desobrigado a atender à demanda social. Embora a educação superior no Brasil seja importante para o desenvolvimento da sociedade, sua trajetória tem sido marcada por situações que necessitam de reformulações, já que muitos cidadãos são excluídos, o que impele à discussão da ampliação do acesso à educação superior via programas sociais.

\section{Programas sociais e ampliação de acesso à educação superior}

Historicamente no Brasil a atuação social se baseia em um modelo de ação assistencial marcado pela intervenção emergencial, sem parâmetros objetivos para definir fundamentos e destinatários, mas que mostra uma tendência recente de mudança, com maior preocupação com critérios de planejamento, e a definição de usuários preferenciais das políticas públicas (Campos e Garcia, 2007). Carvalho (2003) sustenta que programas sociais refletem demandas sociais quando atingem a efetividade, ou não as refletem quando os resultados alcançados não condizem com o planejado, o que tem levado a adaptações na metodologia.

Para Pestana (2001), no setor educacional, duas grandes preocupações dominaram os anos 1960 e 1970: a racionalização de recursos para atender grandes contingentes da população escolarizável, e as reformas necessárias para melhor distribuição social das oportunidades educacionais, evitando que 
essas reproduzissem as desigualdades pela exclusão das classes menos favorecidas. Atualmente, não só o governo está empenhado na criação de meios de desenvolvimento via programas sociais. Há uma tendência social favorável à contribuição das organizações na redução das discrepâncias sociais, e um dos setores no Brasil que necessitam de melhorias, investimentos e desenvolvimento de programas sociais para atender toda a população é a educação. Mancebo (2004) alerta que é necessário acautelar-se contra as saídas pragmáticas, quando se defende a adesão às reformas somente para atender às demandas emergenciais de mercado e quando se buscam soluções para problemas complexos apelando para o assistencialismo e para programas compensatórios.

Visto que a população tem cada vez mais se posicionado contra a exclusão, de qualquer tipo, exigindo a diminuição das desigualdades, o desafio dos programas sociais governamentais é não somente elevar a oferta, mas promover, acima de tudo, a inclusão. Nesse quadro, a educação superior fica em evidência, sendo considerada um segmento apropriado para a promoção de transformações, da independência das pessoas com necessidades educacionais especiais, do conhecimento, e, acima de tudo, da inclusão de grupos minoritários como afrodescendentes, indígenas, mulheres e menos favorecidos financeiramente, bem como amenizar os problemas que possam ocorrer em consequência de sua condição.

Diante da necessidade de desenvolvimento de programas sociais e criação de parcerias, procurando respeitar os parâmetros de qualidade estabelecidos pelos sistemas de ensino, da premência de maior oferta no ensino superior, e, consequentemente, de gerar a inclusão, promovendo a igualdade de acesso, o governo criou um programa social governamental de ampliação do acesso à educação superior que vem provocando intensos debates: O Programa Universidade para Todos (ProUni). Este programa social oferece renúncias fiscais às instituições de ensino superior privadas e, em contrapartida, exige que a isenção seja revertida em bolsas totais ou parciais para estudantes com renda per capita entre 1 e 3 salários mínimos, oriundos do ensino médio público, priorizando negros e indígenas.

Para Catani e Hey (2007), este programa promove o acesso à educação superior aliando baixo custo para o governo, equilíbrio do impacto popular, atendimento às demandas do setor privado e regulagem das contas públicas ao atender à demanda por acesso à educação superior. Mancebo (2004) critica esta iniciativa do governo ao afirmar que, diante da falta de recursos para investimentos, da dívida pública herdada de governos anteriores, propõe uma parceria público-privada para somente conseguir investimentos privados e tentar alavancar o crescimento econômico e a geração de empregos. Nesse 
sentido, o ProUni representaria a retomada de uma tradição de políticas e renúncias fiscais que mais beneficiam o setor privado do que induzem a políticas democratizantes (Catani, Gilioli e Hey, 2006).

A implementação de programas sociais é complexa e divergente do nível do planejamento, onde a inclusão pode ser vista apenas como um meio de amenizar as desigualdades sociais. Para Catani, Gilioli e Hey (2006), o ProUni vem promovendo uma política de acesso à educação superior que não se preocupa com a permanência do estudante, elemento fundamental para a democratização, sendo orientado pela concepção de assistência social e ofertando benefícios, e não direitos, aos bolsistas.

Uma das definições do ProUni que vem causando discussões é a destinação de cotas para autodeclarados negros e indígenas: "geralmente essas cotas são as mais difíceis de preencher, devido ao fato de que negros e indígenas se localizam nos estratos sociais menos favorecidos e, portanto, têm menos condições econômicas de permanecer em um curso superior, ainda que receba as bolsas do ProUni" (Catani e Hey, 2007:421).

Visto que os programas sociais são definidos como meios de combate às desigualdades e à necessidade de maiores investimentos em educação no país, o governo federal implementou o ProUni com a finalidade de ampliação das vagas no ensino superior, gerando maior acessibilidade da população carente a esse nível de ensino. Contudo, como programas como este podem ter seu desempenho avaliado?

\section{Desempenho de programas sociais}

Cunha (2008) afirma existirem diversas formas de realizar uma avaliação, e uma delas é acadêmica, mais formal, enfocando o estudo da efetividade das políticas, seus impactos e benefícios, o que integra o escopo deste estudo, ao tratar das percepções dos beneficiários sobre o alcance de resultados. Para Carvalho (2003), a avaliação de desempenho de programas sociais é um processo contínuo que observa todas as fases, da identificação do problema à análise das mudanças sociais ocorridas a partir da intervenção pública: a avaliação se dá ao longo do processo, nos impactos e efeitos causados. "Na avaliação de programas sociais, estão implícitos o julgamento de valor, a partir do qual, decisões são tomadas e destinos traçados" (Pogoda, Pires e Moretti, 2003:2). Assim, este tipo de avaliação de desempenho pode ser esclarecedor e norteador de decisões, já que observar o processo permite conhecimento e compreensão das ações públicas e de possibilidades de ade- 
quação dos programas às necessidades dos beneficiários, na implementação e nos resultados.

A análise de desempenho do programas sociais é necessária para que se atinjam melhores resultados ao se usar e controlar os recursos aplicados, sendo preciso avaliar se os programas atendem ou não às pressões e demandas sociais. Faria (2001) afirma a importância da discussão da avaliação do processo de tomada de decisão, e, principalmente, da aferição de resultados e impactos de políticas e programas sociais, pois os efeitos repercutem em toda a sociedade. Para analisar o desempenho é importante atentar para se os beneficiários realmente usufruem os recursos destinados, se os processos ocorrem como planejado, se as ações proporcionam aos beneficiários o que realmente precisam, desejam e esperam. A avaliação de programas não pode se basear apenas em noções sobre a realidade dos membros de uma minoria, mas incorporar os atores sociais para alcançar eficiência e equidade (Melo, 2001).

Para Arretche (2001), qualquer forma de avaliação de uma política ou programa público envolve necessariamente um julgamento, uma atribuição de valor, uma medida de aprovação ou desaprovação, a partir de certa concepção de justiça (explícita ou implícita). Esta autora sustenta que, para a avaliação de políticas públicas e programas sociais, é necessário analisar sua eficiência, eficácia e efetividade. A avaliação da eficiência considera a relação entre o esforço empregado na implementação de uma dada política ou programa social e os resultados alcançados, uma lógica econômica com foco na racionalização de recursos mais do que no alcance de resultados (Saraiva e Gonçalves, 2008). Para Arretche (2001), este tipo de avaliação é o mais urgente a ser desenvolvido devido: a) à escassez de recursos públicos, que exige racionalização do gasto; b) às populações a serem atendidas pelos programas sociais serem de enormes proporções, o que exige maior controle; e c) à competência e eficiência no uso dos recursos publicamente apropriados, uma condição para a confiança pública no Estado e nas instituições democráticas.

Ao se adotarem parâmetros de eficácia para a avaliação de programas sociais, o foco está nos resultados alcançados, o que possibilita verificar, grosso modo, com base nas informações disponíveis, seu fracasso ou sucesso (Arretche, 2001). Como se refere ao "grau em que a organização realiza suas metas" (Daft, 2002:58), diz respeito a uma racionalidade produtiva, em que é mais relevante ao que se chega como produto do que como o resultado foi alcançado. Programas sociais efetivos são aqueles em que os envolvidos com a produção ou com a recepção dos programas têm suas expectativas e necessidades satisfeitas. A percepção de realização adquire relevância superior a 
aspectos mais formais, uma vez que, quando se considera a necessidade de ajustes de programas sociais para considerar as necessidades dos cidadãos, é a efetividade o parâmetro de desempenho em questão, pois é a racionalidade social que define e avalia o alcance de resultados.

Por isso, no processo de avaliação de desempenho, é importante o envolvimento não só das agências responsáveis pela implantação, mas de todos os envolvidos, inclusive os beneficiários, para que se possam mensurar os processos. A avaliação participativa permite aflorar as diversas "verdades" sobre os propósitos e resultados do programa ou ação institucional. Carvalho (2001) defende que a participação dos envolvidos na ação garante à avaliação maior densidade, limitando o risco de se tornar periférica. Para Pogoda, Pires e Moretti (2003), a avaliação de desempenho é mais do que mera questão fiscalizadora ou controladora, levando a uma intensa reflexão que deve ser feita com todos os envolvidos no processo. Faria (2001) complementa esta visão ao afirmar que o objetivo primordial da avaliação dos programas sociais é apurar sua capacidade de oferecer adequada atenção aos cidadãos; assim, a avaliação é parte essencial da formulação e implementação dos programas sociais, contribuindo para seu aperfeiçoamento. Daí porque neste texto a efetividade foi adotada como parâmetro de desempenho, conforme será detalhado na próxima seção.

\section{Método}

Neste estudo se analisa a efetividade de programas sociais de acesso à educação superior a partir da ótica de seus beneficiários, o que foi feito pela observação do caso do ProUni, programa social governamental. A abordagem adotada nesta pesquisa foi qualitativa, baseada em entrevistas individuais em profundidade. Na pesquisa, do tipo descritiva, dadas as impossibilidades objetivas de abordar todos os milhares de beneficiados do programa no país, optou-se por delimitar os sujeitos de pesquisa vinculados como estudantes regulares de uma instituição de ensino superior, situada em Minas Gerais, que aderiu ao ProUni desde o primeiro momento. No primeiro semestre de 2008, período em que os dados foram coletados, havia 246 bolsistas estudando na referida IES. Destes, tornaram-se efetivamente sujeitos de pesquisa 11 estudantes, todos do curso de administração, escolhidos em função de terem sido selecionados para serem bolsistas parciais ou integrais, no máximo até o terceiro período do curso. Este critério foi considerado adequado para captar as visões de bolsistas 
do programa por pelo menos dois anos e meio, tempo suficiente para formar opiniões com base em uma vivência prolongada do ProUni.

A pesquisa de campo foi realizada nas instalações da instituição de ensino superior. O protocolo de pesquisa inicialmente se dava por meio de uma explanação dos objetivos do estudo, de modo que os entrevistados pudessem conhecer seus propósitos e contribuir da forma que julgassem conveniente. Em seguida, os entrevistados eram encorajados a expressar sentimentos, crenças e valores, além dos relatos pessoais da percepção do programa de governo. Para a coleta de dados foi usado um instrumento semiestruturado de entrevista, elaborado com o objetivo de coletar os dados necessários para análise dos pontos de vista de cada entrevistado. O conteúdo do roteiro de coleta de dados era dividido em três blocos: a) Socialização e trajetória educacional até ensino médio; b) Processo de admissão no ensino superior e permanência no programa social; e c) Contexto do objeto de pesquisa - programa social e ProUni (representação e desempenho do programa de governo). Este instrumento foi adequado por permitir maior interação no momento das entrevistas a partir de um diálogo informal, em que eram observados e registrados, além das falas, os comportamentos e reações dos entrevistados, material gravado e, posteriormente, transcrito na íntegra.

Os dados foram examinados com base na análise do discurso, assumindo, já que os depoimentos selecionados dos entrevistados são enunciados discursivos, "práticas socialmente embasadas, que apresentam, explícita ou implicitamente, as marcas da ideologia que os constitui, não sendo, portanto, neutros" (Saraiva et al., 2009: 17), que dizem mais do que o articulado por meio da fala (Bakhtin, 2006). Foram adotados diversos procedimentos de análise das estratégias discursivas usadas pelos enunciadores. Estes envolveram: a) análise dos principais aspectos da análise lexical; b) análise dos principais temas e figuras (explícitos ou implícitos) dos discursos, inclusive os personagens; c) análise dos principais percursos semânticos estruturados a partir dos temas e figuras; d) análise dos principais aspectos interdiscursivos e intradiscursivos; e) análise dos principais aspectos da sintaxe discursiva; e f) análise dos principais aspectos refletidos e refratados nos discursos.

\section{Análise dos dados}

Após o tratamento inicial, os dados foram trabalhados em algumas categorias discursivas, obtidas por meio do uso dos procedimentos apontados. Como os discursos dizem respeito a um ato de enunciação embasado socialmente, é 
preciso saber quem os enuncia. Os entrevistados são estudantes, com idade entre 21 e 27 anos, tendo passado pelo Enem entre 2002 e 2004, e escolhido o curso de administração na inscrição do ProUni como primeira opção. Sete moram na cidade em que a IES se situa e quatro em cidades da região. Todos são solteiros e moram com os familiares, possuem casa própria e se classificam como membros da classe média. Sete dos entrevistados possuem bolsa de $100 \%$ e quatro, de 50\%, todos usuários do Fies para arcar com o restante da mensalidade. Dos entrevistados, seis se classificaram como brancos, três como pardos e dois como negros. Todos estudaram em escola pública e criaram diversas expectativas em relação a poderem estudar em uma instituição de ensino superior particular com uma bolsa de estudos oriunda de um programa do governo federal.

\section{Expectativas quanto ao ProUni}

Os discursos reforçam Catani e Hey (2007) quanto ao problema de acesso e permanência dos estudantes na educação superior, sendo o ProUni visto como uma solução:

(01) eu tentei o ProUni por saber que era bolsa e eu hoje, se não fosse a bolsa, estaria até estudando, mas com muita dificuldade [...] e deixando outras [coisas de lado] e deixando [as dívidas] virar uma bola de neve. (entrevistado 10)

(02) é uma iniciativa que tomou todo o Brasil e está mudando a realidade de muita gente, para melhor, e espero que só melhore daqui para frente, e que o governo invista mais, já que não mexe na escola pública, pelo menos dê essa solução. (entrevistado 9)

(03) Olha, eu acho que o ProUni foi uma das melhores estratégias do governo, pois se realmente queria incluir a classe menos favorecida, conseguiu, e também a quantidade de pessoas que estão conseguindo realizar o sonho de entrar na faculdade aumentou. (entrevistado 10)

Conforme os fragmentos discursivos (01), (02) e (03), a iniciativa do governo é representada como possibilidade de inclusão (conforme a seleção lexical "se realmente queria incluir a classe menos favorecida, conseguiu") e concretização de sonhos (seleção lexical "a quantidade de pessoas que estão conseguindo realizar o sonho de entrar na faculdade aumentou"), sendo o 
ProUni associado à mudança na vida dos por ele beneficiados ("está mudando a realidade de muita gente"). Os fragmentos discursivos se posicionam quanto à efetividade do programa, pois dizem respeito ao acesso que o programa proporciona, como condição imprescindível de acesso (fragmento discursivo 01), à mudança trazida pelo usufruto das prerrogativas do programa (fragmento discursivo 02), e à avaliação da inclusão e da realização das minorias historicamente excluídas (fragmento discursivo 03), aspectos que se relacionam ao desempenho do ProUni quanto a expectativas e a resultados alcançados.

A avaliação do desempenho de programas é algo complexo, conforme Carvalho (2003), tanto que no mesmo fragmento discursivo em que é explicitada a mudança na vida dos beneficiados por meio do programa, há uma crítica ao governo e à qualidade das escolas públicas (implícito subentendido). Um implícito pressuposto é que este programa aparece como um paliativo, conforme a expressão "pelo menos", que sugere uma alternativa em face da não melhoria da educação pública. Outro implícito pressuposto a partir desta seleção lexical é que o governo transfere a responsabilidade de inclusão para o ensino particular, o que está de acordo com Vaidergorn (2001), ao criticar medidas do governo que facilitam a proliferação de cursos particulares, possibilitando-lhes mais lucratividade, e desobrigando o governo de atender a demanda social e a inclusão.

\section{O ProUni e a inclusão}

Possivelmente, até mesmo por conta dos objetivos explícitos do programa, a inclusão é um elemento que aparece com frequência nos depoimentos, conforme pode ser visto a seguir:

(04) [O ProUni é] uma grande oportunidade de continuar meus estudos e toda vida eu não admitia pagar uma faculdade, sendo que eu estudei a vida toda em escola pública. Então para mim é mais [do] que justo o governo criar esse programa como mais um meio de incluir as pessoas menos favorecidas no ensino superior, e mais [do] que justo [que ele seja] para as pessoas que estudaram em escola pública. (entrevistado 6)

(05) Saí do terceiro ano e fui direto para a faculdade, e para mim foi um privilégio, porque eu nunca teria estrutura para fazer isso [ingressar no ensino superior] sabe?! [...] a minha família era meio sem condições e [o ProUni] abriu 
muitas portas para mim, muitas mesmo, então eu me considero uma pessoa de muita sorte. (entrevistado 9)

(06) Olha, para mim, primeiro [é] uma vitória, realmente uma vitória que eu não esperava, igual esperava muito mais dificuldade para estar aqui, não que não tenha, mas eu posso me dedicar muito mais aos estudos [...]. (entrevistado 10)

Estes fragmentos discursivos são explícitos e variados quanto ao ProUni, representado por expressões como "grande oportunidade", "privilégio" ou como "vitória", um implícito subentendido de que o programa é valorizado por lhes proporcionar inclusão em um ambiente ao qual não teriam acesso de outra forma. A inclusão aparece como aspecto refratado ${ }^{1}$ nos depoimentos, uma vez que não se trata de algo a que se tem direito por ser cidadão, tal como refletido na legislação, mas uma espécie de dádiva à qual se tem acesso por "sorte", por exemplo, conforme o fragmento discursivo (05). Os entrevistados associam limitações socioeconômicas (conforme a seleção lexical "a minha família era meio sem condições", do fragmento discursivo 05) a dificuldades de ingresso na educação superior (seleção lexical "esperava muito mais dificuldade para estar aqui", do fragmento discursivo 06), mas acreditam que o programa inclui os menos favorecidos, sendo-lhe associado um senso de justiça, conforme a seleção lexical "é mais [do] que justo o governo criar esse programa como mais um meio de incluir as pessoas menos favorecidas" (fragmento discursivo 04).

Um implícito pressuposto do fragmento discursivo (04) é que o beneficiário do programa considera o governo responsável por promover a possibilidade de continuidade dos estudos aos menos favorecidos, alegando que considera justo que haja mais pessoas no ensino superior, desde que tenham sido estudantes do ensino público (implícito pressuposto). Esta visão evidencia o significado social do programa ao reduzir a defasagem de acesso da população menos favorecida à educação superior. Porém, a inclusão de grupos minoritários étnicos tem causado discussões, principalmente no que tange a quotas.

\footnotetext{
${ }^{1}$ Refração linguística é uma estratégia discursiva analisada por Bakhtin (2006), que parte da ressignificação dos temas nos discursos. Todo aspecto é, ao mesmo tempo, refletido linguisticamente, preservando seu sentido socialmente estabelecido, e refratado, isto é, reinterpretado conforme os referenciais dos enunciadores. Um discurso, assim, reproduz (ou reflete) as condições sociais em que é produzido, e modifica (ou refrata) determinados aspectos, de acordo com as ressignificações de seus enunciadores.
} 


\section{O ProUni e a questão das quotas}

Os depoimentos (07) e (08) desaprovam as quotas, o que é explicitado por meio das seleções lexicais "acho que ninguém tem que ser avaliada pelas suas origens e sim pela sua capacidade" (fragmento discursivo 08) e "acho que tem uma questão de até [...] racismo [...] porque branco, negro, qualquer um é igual" (fragmento discursivo 09).

(07) Eu sou contra a qualquer tipo de quota. Acho que ninguém tem que ser avaliada pelas suas origens e sim pela sua capacidade [...] eu acho que tem que ter um processo seletivo normalmente, porque você é negro, você é índio, o que for [...] seu lugar já está garantido. (entrevistado 5)

(08) Acho que tem uma questão de até [...] racismo [...] porque branco, negro, qualquer um é igual, então [a vaga] deve ser de qualquer um que não tenha condições financeiras para arcar com as despesas desse tipo de ensino. (entrevistado 6)

Os argumentos explicitam que diferenças com base na etnia são discriminatórias, e que não devem ser consideradas na formulação de políticas públicas, o que não ocorre se o nível socioeconômico é colocado em pauta ("[a vaga] deve ser de qualquer um que não tenha condições financeiras para arcar com as despesas desse tipo de ensino"). Outra evidência da falta de efetividade do programa com relação às quotas é vista no fragmento discursivo (09):

(09) Eu acho interessante [a política de quotas], mas eu acho que não funciona muito. [...] Acho que não, todos são iguais, todos têm a mesma capacidade só que uns estudaram mais e outros estudaram menos, eu acho que é bom ter oportunidade para quem estudou menos independente de ser negro ou indígena. $\mathrm{E}$ também acho que a seleção também, tipo assim, como definir quando é negro quando é indígena também é complicado porque, você perguntou qual a minha cor, sabe, branca, mas se eu ficar um pouquinho no sol eu vou ficar morena e quem vai falar comigo que eu não sou negra, entendeu? Qual o critério usado? Então, como que vai provar se eu sou negra ou branca [...]. Então eu acho que é difícil isso, talvez uma pessoa que tem mais condições se declara negra, talvez pega uma vaga de uma pessoa que talvez tivesse menos chance de entrar no ensino superior, só porque a outra é branca, entendeu? Acho que deveria incluir uma classe, não cor ou raça. Acho que não é válido. (entrevistado 7) 
No fragmento discursivo (09), quando a entrevistada afirma ser difícil definir etnias (seleção lexical "como definir quando é negro quando é indígena também é complicado"), implicitamente subentende-se alusão à miscigenação no Brasil. Em um país com população predominante mestiça, a concessão de vagas para autodeclarados negros e indígenas é polêmica, pois pode gerar resultados duvidosos, já que os critérios étnicos são de complexa comprovação ("como definir quando é negro quando é indígena? (...) qual o critério usado?"), dificultando as diferenças e abrindo oportunidades para fraudes ("talvez uma pessoa que tem mais condições se declara negra, talvez pega uma vaga de uma pessoa que talvez tivesse menos chance de entrar no ensino superior, só porque a outra é branca, entendeu?").

É interessante notar que a condição socioeconômica, outra forma de diferenciar os cidadãos, não é considerada um critério de desigualdade:

(10) Não concordo no aspecto de raça. Concordo no aspecto socioeconômico, realmente as pessoas que têm menor poder aquisitivo, famílias de classe inferior têm que ter esse benefício. Acho que isso é fundamental para que as pessoas de classe mais baixa tenham acesso ao curso superior, mas, a outra vertente que relacionada à raça eu discordo totalmente. Um país que preza a igualdade, direitos iguais, igual o nosso, não deveria ter nem isso, nem outros itens como quotas para negros em universidades. (entrevistado 8)

(11) [...] porque eu acho que desigualdade nesse país nós temos por todos os lados, é lógico que desde [...] quando o Brasil foi descoberto, os negros e índios vêm sofrendo mais que os brancos, só que ao mesmo tempo, hoje tem muita gente na mesma situação deles. Então eu acho que a bolsa deve ser para todos. (entrevistado 9)

Tal fato é possivelmente explicado pelas seleções lexicais "é fundamental para que as pessoas de classe mais baixa tenham acesso ao curso superior" e "só que ao mesmo tempo, hoje tem muita gente na mesma situação deles", respectivamente dos fragmentos discursivos (10) e (11). Percebem-se, no fragmento discursivo (11), aspectos interdiscursivos e intradiscursivos. De um lado, implicitamente, subentende-se a desigualdade como uma característica que os brasileiros compartilham ("desigualdade nesse país nós temos por todos os lados"). De outro, narra-se em terceira pessoa a situação "deles", de negros e índios que sofreram mais do que os brancos quando do descobrimento do Brasil, o que vivenciam hoje "outros", conforme a seleção lexical "hoje tem muita gente na mesma situação deles". O narrador se coloca de fora das 
duas esferas, pondo-se à distância dos negros e índios, e das pessoas que hoje sofrem tanto quanto eles, um exemplo de interdiscursividade ao opor intradiscursivamente o sofrimento, que é histórico e compartilhado por vários grupos sociais, à posição do narrador que se distancia da situação ao descrevê-la.

\section{A inserção na educação superior particular e a exclusão}

A inserção de estudantes oriundos do ensino público na instituição de ensino superior particular observada e sua interação com outros grupos sociais não são marcadas pela exclusão, como seria de se esperar em um contexto de "pagantes" e "não pagantes":

(12) Tem esse tipo de preconceito não, pelo contrário as pessoas encaram com naturalidade, como se o aluno do ProUni estivesse pagando a faculdade. (entrevistado 8)

(13) nunca tivemos uma situação de precisar "brigar" para sermos respeitados, pois o processo foi bem natural. (entrevistado 9)

(14) [...] nunca houve preconceito, até mesmo porque estamos inseridos num quadro bem parecido, todo mundo trabalha, paga sua faculdade, tem certa dificuldade para pagar, não estamos num cenário onde não há classes muito distintas. (entrevistado 10)

Na percepção dos entrevistados, houve uma receptividade positiva ao serem inseridos no contexto de uma instituição de ensino superior particular, não dificuldades de aceitação, conforme os fragmentos discursivos (12), (13) e (14). Em parte isso pode ser explicado em razão do contexto local, conforme explicitado na seleção lexical "até mesmo porque estamos inseridos num quadro bem parecido, todo mundo trabalha, paga sua faculdade, tem certa dificuldade para pagar" do fragmento discursivo (14).

(15) [Na] faculdade no geral não tem essa separação, não há um privilégio para os alunos bolsistas com relação aos pagantes, pelo contrário, ela quer igualar e deixar rolar, a não ser com relação a pedidos da secretaria ou bibliotecas, nas taxas que acabamos recebendo descontos. Ela se dispôs a ajudar a todos, não só do ProUni com aulas de monitorias. (entrevistado 9) 
O implícito pressuposto do fragmento discursivo (15) é que a IES tem um papel importante na diminuição das desigualdades e do eventual preconceito para com os beneficiários do ProUni, não tendo sido observados efeitos negativos neste ambiente. Para os entrevistados, eles somente foram percebidos como bolsistas do programa por serem os primeiros a usufruí-lo, e que a inserção se deu de maneira natural.

(16) Por sermos os primeiros alunos beneficiados pelo programa, éramos meio que destaque com relação aos pagantes, às vezes tinham uns que faziam piadinhas do tipo, "olha os filhos do Lula", mas com muita naturalidade e mesmo por descontração, por isso sabemos quem é ou não do ProUni na sala, mas no contexto geral, a sala é bem unida e nem percebemos quando somos ou não do ProUni quando o assunto é lutar pelos direitos, pois nos misturamos no meio da massa e nos tornamos um grupo só. A única diferença é que temos uma ajuda do governo para continuarmos na faculdade, mas somos tratados de igual para igual. (entrevistado 10)

O fragmento discursivo (16) indica aspectos intradiscursivos e interdiscursivos. Eles ficam explícitos na reprodução do discurso "bem humorado" dos estudantes pagantes sobre os bolsistas, conforme a seleção lexical "olha os filhos do Lula", o que marca sua diferença com base na capacidade de pagamento das mensalidades da IES. E são reforçados à medida que o narrador, que se inclui no final do fragmento discursivo, coloca que "a única diferença é que temos uma ajuda do governo para continuarmos na faculdade". A intradiscursividade se baseia em uma diferença dos discursos dos que riem dos que precisam da ajuda do governo dos que enunciam que precisam deste auxílio para continuar seus estudos.

Quanto às diferenças de inserção dos estudantes oriundos da rede pública de ensino em uma instituição de ensino superior particular, os depoimentos não revelam maiores problemas, apenas os normalmente observados em uma situação de mudança de ambiente. Embora os entrevistados confirmem dificuldades no início, estas foram menos relacionadas à qualidade do que à adaptação ao ritmo da educação superior. Nos casos de dificuldades específicas, houve um suporte institucional:

(17) Porque nas matérias que eu tinha dificuldade havia monitores, aí foi fácil. (entrevistado 4)

(18) Ela [a faculdade] se dispôs a ajudar a todos, não só do ProUni com aulas de monitorias. (entrevistado 9) 
Os estudantes com dificuldades foram tratados de maneira semelhante, sendo-lhes proporcionadas aulas para o nivelamento do aprendizado, não direcionadas apenas aos beneficiários do ProUni. Para os entrevistados, a base recebida no ensino público é compatível com as exigências da educação superior privada analisada. Em face das críticas sobre a qualidade do ensino público, duas hipóteses podem ser levantadas: ou o ensino não possui problemas tão graves quanto os apresentados, ou a qualidade da educação superior privada é deficiente, o que confirmaria a perspectiva de Barreiro e Terribili Filho (2007).

\section{O desempenho da ótica da inserção no mercado de trabalho}

Um parâmetro para avaliar a efetividade do programa social em questão diz respeito à inserção no mercado de trabalho, uma vez que falhas no ProUni trariam como consequência direta problemas de colocação profissional. Os depoimentos a seguir tratam deste aspecto:

(19) [Há] novas portas se abrindo com certeza e através da faculdade. Estou pensando em ter um projeto de abrir um negócio pra mim. (entrevistado 4)

(20) estar fazendo faculdade cria mais expectativas, além do conhecimento que você adquire, sua autoestima melhora e você tem mais força para correr atrás e se realizar, então penso que o ProUni é um programa que ensina a pescar, e não dá os peixes. (entrevistado 10)

Os fragmentos discursivos (19) e (20) explicitam posicionamentos de efetividade que passam pela perspectiva de empreendedorismo empresarial e de realização profissional. No primeiro caso, implicitamente se pressupõe que as "novas portas" a que o enunciador alude se referem a oportunidades profissionais, que ele associa à presença na faculdade. Indiretamente, ao proporcionar o acesso à educação superior, o ProUni neste caso emancipa o estudante a ponto de ele projetar um futuro em que atuará como empresário, conforme a seleção lexical "estou pensando em ter um projeto de abrir um negócio pra mim". No segundo caso, estudar no nível superior implica a criação de expectativas associadas à autorrealização, o que traz melhoria da autoestima, o que implicitamente se pressupõe que também no nível pessoal.

Outro indicador de efetividade do ProUni se refere à atuação profissional dos entrevistados. O nível de desemprego diminuiu ou, para os que 
ainda não trabalhavam, oportunidades surgiram por eles estarem no ensino superior, o que os preparou melhor para as exigências do mercado. Há entre eles expectativas de que, em razão de sua formação superior, melhores oportunidades de emprego surjam, para as quais poderão concorrer em igualdade de condições com outros profissionais, o que representa inclusão e desenvolvimento pessoal.

(21) Quanto ao meu emprego, eu já trabalhava, só que o ProUni me deu uma chance de realizar o sonho de correr atrás de um emprego melhor, e ter condições de concorrer com pessoas que estavam no mercado, de igual para igual. (entrevistado 9)

(22) Hoje estou numa posição bem melhor, num serviço mais confortável e que me dá uma expectativa de aprendizado tanto na área que estudo, quanto de melhoria salarial, então houve muita mudança. (entrevistado 10)

(23) Eu pretendo ter meu próprio negócio... não quero entrar em nenhuma empresa [...] então estar estudando, serviu para abrir minha mente, ter mais conhecimentos, ter uma visão mais aberta de mundo [...] para ter meu próprio negócio. (entrevistado 6)

De acordo com os depoimentos (21), (22) e (23), o programa atende a expectativas de melhoria profissional para os entrevistados, existindo um efeito direto da escolaridade na remuneração, o que é explícito nas seleções lexicais "o ProUni me deu uma chance de realizar o sonho de correr atrás de um emprego melhor, e ter condições de concorrer com pessoas que estavam no mercado, de igual para igual" (fragmento discursivo 21) e "hoje estou numa posição bem melhor, num serviço mais confortável e que me dá uma expectativa de aprendizado tanto na área que estudo, quanto de melhoria salarial" (fragmento discursivo 22). Esses fragmentos discursivos ainda revelam uma estratégia discursiva que opõe temporalmente o "antes" ao "depois" do programa, indicando melhorias durante o processo. É explícita a percepção de efetividade do programa, que por meio de possibilidades de recolocação profissional parece aos entrevistados como bem-sucedido em seu objetivo de inclusão. É ainda mais explícita a efetividade no caso do fragmento discursivo (24). O entrevistado vale-se do que aprende na IES para construir expectativas sobre um futuro profissional em que ele pretende ter seu próprio empreendimento. Estes depoimentos reforçam os argumentos de Lucchesi (2005) de que a educação superior é de grande importância para a melhoria de uma socieda- 
de, à medida que pessoas são qualificadas para obter emprego e remuneração melhores no mercado de trabalho.

\section{Considerações finais}

O objetivo neste estudo é analisar a efetividade de programas sociais de acesso à educação superior a partir da ótica dos seus beneficiários, o que foi feito mediante a observação do Programa Universidade para Todos. Onze estudantes de uma instituição de ensino superior privada foram entrevistados individualmente e em profundidade sobre o programa, o que foi gravado, transcrito e tratado por meio de técnicas de análise do discurso. Os principais resultados sugerem que o ProUni cumpre seus objetivos por proporcionar o acesso à educação superior de segmentos sociais desfavorecidos do ponto de vista socioeconômico, embora a inclusão via quotas com base em etnia seja condenada. Estar em um curso superior implica melhorias nas oportunidades e nas posições profissionais e na remuneração, o que repercute sobre a autoestima e as expectativas dos bolsistas, que veem seu futuro de forma positiva.

As evidências encontradas, se, por um lado, apontam para um programa efetivo aos olhos dos seus bolsistas, à medida que satisfaz às suas expectativas imediatas de acesso à escolaridade superior e lhes proporciona efeitos positivos, por outro, mostram problemas de desempenho, uma vez que não consegue concretizar, de fato, o acesso à educação, tal como previsto na Constituição Federal. Em vez de a oferta de vagas das universidades públicas ser ampliada conforme as demandas dos cidadãos, o que se verifica é um estímulo à proliferação das instituições de ensino superior particulares, que abrem suas portas em troca de isenções fiscais, o que indica que muito precisa ser feito para uma significativa mudança no segmento.

As principais contribuições deste estudo se referem à avaliação de desempenho de programas sociais da ótica dos seus beneficiários, uma vez que ainda são relativamente poucas as pesquisas que se voltam para os cidadãos, suas expectativas e necessidades. E isso é imprescindível, uma vez que, em alguns casos, o que é considerado um planejamento adequado para os que desconhecem as necessidades do público-alvo é contraproducente da ótica dos que usufruem os serviços. Como é o cidadão a razão de ser dos serviços públicos, é preciso considerar prioritariamente seus posicionamentos tanto ao se planejar quanto ao se avaliar os programas sociais que lhe são destinados.

No que se refere ao ensino e à pesquisa, às organizações e à sociedade, algumas questões se colocam: seriam as práticas de ensino e pesquisa 
adequadas a estudantes com deficiência generalizada por serem oriundos das precárias condições das escolas públicas? Se sim, até que ponto as concepções e práticas educacionais vigentes nas IES se comprometem com a emancipação dos profissionais que formam? Seriam os profissionais apenas ajustados ao que o mercado precisa? Se sim, seria este o papel que se espera da educação superior? A inclusão a que se alude no programa se limita às instituições de ensino superior? Criar oportunidades profissionais após a graduação não seria atribuição do governo, como meio de concretizar a emancipação social? As organizações estão preparadas para receber os profissionais beneficiados por programas de acesso à educação superior como o ProUni? Qual a legitimidade que a sociedade confere a programas sociais comprometidos apenas superficialmente com o atendimento de suas necessidades? Tais questões sugerem uma extensa agenda de pesquisa e a necessidade de reformulações em iniciativas como a do ProUni, para que seu slogan "Universidade para todos" realmente se concretize.

\section{Referências}

ARRETCHE, M.T. Tendências no estudo sobre avaliação. In: CARVALHO, M.C.B. et al. Avaliação de políticas sociais: uma questão em debate. 3. ed. São Paulo: Cortez, 2001. p. 29-41.

BAKHTIN, M. (Voloshinov). Marxismo e filosofia da linguagem. 8. ed. São Paulo: Hucitec, 2006.

BARBOSA, M.M. A inclusão e a diversidade no ensino superior. Educação e Mudança, Anápolis, n. 9/10, p. 15-29, jan./dez. 2002.

BARREIRO, I.M.F.; TERRIBILI FILHO, A. Educação superior no período noturno no Brasil: políticas, intenções e omissões. Ensaio: avaliação de política pública da Educação, Rio de Janeiro, v. 15, n. 54, p. 81-102, jan./mar. 2007.

BARRETO, F.C.S.; SCHWARTZMAN, J. Ensino superior no Brasil: crescimento e alternativas. Educação Brasileira, Brasília, v. 21, n. 42, p. 11-39, jan./jun. 1999.

BRASIL, Lei no 10.172, de 9 de janeiro de 2001. Aprova o Plano Nacional de Educação, e dá outras providências. Diário Oficial da República Federativa do Brasil, Brasília, 10 jan. 2001.

CAMPOS, C.E.A.; GARCIA, J. Contribuições para a supervisão dos programas sociais com foco na família. Revista Katálysis, Florianópolis, v. 10, n. 1, p. 318-345, jan./jun. 2007. 
CARVALHO, M.C.B. Avaliação participativa - uma escolha metodológica. In: CARVALHO, M.C.B. et al. Avaliação de políticas sociais: uma questão em debate. 3. ed. São Paulo: Cortez, 2001. p. 87-94.

CARVALHO, S.N. Avaliação de programas sociais: balanço das experiências e contribuição para o debate. São Paulo Perspectiva, São Paulo, v. 17, n. 3-4, p. 201-225, jul./dez. 2003.

CATANI, A.M.; GILIOLI, R.S.P.; HEY, A.P. ProUni: democratização de acesso às Instituições de Ensino Superior? Educar, Curitiba, n. 28, p. 125-140, 2006.

CATANI, A.M.; HEY, A.P. A educação superior no Brasil e as tendências das políticas de ampliação de acesso. Atos de pesquisa em educação, Blumenau, v. 2, n. 3, p. 414-429, set./dez. 2007.

CUNHA, C.G.S. Avaliação de políticas públicas e programas governamentais: tendências recentes e experiências no Brasil. Disponível em: <http//ww.seplag.rs.gov. br>. Acesso em: 25 maio 2008.

DAFT, R.L. Organizações. São Paulo: Pioneira, 2002.

FARIA, R.M. Avaliação de programas sociais - evoluções e tendências. In: CARVALHO, M.C.B. et al. Avaliação de políticas sociais: uma questão em debate. 3. ed. São Paulo: Cortez, 2001. p. 41-49.

LUCCHESI, M.A.S. La universidad en el contexto de la postglobalizacion: políticas públicas para la universidad brasileña en el umbral del siglo XXI. Educere, Mérida, v. 9, n. 29, p. 199-206, Mayo/Jun. 2005.

MANCEBO, D. Reforma universitária: reflexões sobre a privatização e a mercantilização do conhecimento. Educação e Sociedade, Campinas, v. 25, n. 88, p. 845-866, out. 2004.

MEC. Ministério da Educação. O programa. Disponível em: < http://portal.mec.gov. $\mathrm{br} /$ prouni/index.php?option $=$ com_content\&task $=$ view\&id $=124 \&$ Itemid $=140>$. Acesso em: 25 jun. 2009.

MELO, M.A. As sete vidas da agenda pública brasileira. In: CARVALHO, M.C.B. et al. Avaliação de políticas sociais: uma questão em debate. 3. ed. São Paulo: Cortez, 2001. p. 11-28.

PESTANA, M.I.G.S. Avaliação educacional — o sistema nacional de avaliação da educação básica. In: CARVALHO, M.C.B. et al. Avaliação de políticas sociais: uma questão em debate. 3. ed. São Paulo: Cortez, 2001. p. 53-63.

POGODA, C.F.; PIRES, J.T.; MORETTI, T. Avaliação de resultados de projetos e programas sociais. In: SEMINÁRIOS EM ADMINISTRAÇÃO, VI, 2003, São Paulo. Anais... São Paulo: FEA/USP, 2003. 
SAMPAIO, H. Ensino superior no Brasil: o setor privado. São Paulo: Hucitec/fapes, 2000.

SARAIVA, L.A.S. et al. Introdução. Estudos organizacionais e análise do discurso: aproximações possíveis. In: CARRIERI, A.P. et al. (Org.). Análise do discurso em estudos organizacionais. Curitiba: Juruá, 2009. p. 11-19.

SARAIVA, L.A.S.; GONÇALVES, N.R. Democratização do poder local e efetividade de programas sociais: análise de uma experiência municipal. RAC-Eletrônica, Curitiba, v. 2, n. 3, p. 392-409, set./dez. 2008.

SOUSA, S.M.Z.; FREITAS, D.N.T. Políticas de avaliação e gestão educacional - Brasil, década de 1990 aos dias atuais. Educação em Revista, Belo Horizonte, v. 40, n. 24, p. 194-201, dez. 2004.

SOUZA, M.I.S. Os empresários e a educação. Petrópolis: Vozes, 1981.

VAIDERGORN, J. Uma perspectiva da globalização na universidade brasileira. Caderno Cedes, Campinas, v. 21, n. 55, p. 78-91, nov. 2001. 